\title{
Aspects of molecular phenotype and its correlations with breast cancer behaviour and taxonomy
}

\author{
AM Hanby ${ }^{*}$, \\ 'Academic Unit of Pathology, Leeds University, Clo Department of Histopathology, St James's University Hospital, Beckett Street, Leeds LS9 7TF, UK
}

The assessment of breast cancer morphology remains an important element in the evaluation of prognosis and therapeutic planning for this disease. The tumour morphology reflects the molecular profile that produced it and consequently each can be predictive of the other.

British Journal of Cancer (2005) 92, 613-617. doi: 10.1038/sj.bjc.660242I www.bjcancer.com

Published online 8 February 2005

(c) 2005 Cancer Research UK

Keywords: breast; taxonomy; prediction; research; grade

The morphological attributes of a breast cancer, as assessed by histological examination, supply the breast cancer care team with invaluable prognostic and predictive information. Notwithstanding the great advances in molecular techniques available to study such tumours, morphology remains indispensable. Studies of most large cohorts of unselected breast cancers continue to show that grade, nodal status and tumour size remain the most powerful prognostic indicates in a multivariable analysis. It is these that are combined in the Nottingham Prognostic Index, the most widely used prognostic tool in use in the UK (Balslev et al, 1994). This is not to suggest that molecular events are not important, but morphology, the visual consequence of a chaotic interplay of multiple molecular alterations is readily analysed and interpreted. Interestingly, in order to comprehend the results of some cDNA array work, analysis has involved the elaboration of complex diagnostic representations of data - a neomorphological approach that surely reinvents the wheel.

Tumour size and nodal status are very much temporal factors, whereas grade is very much a morphological attribute and is qualitative. In other words, grade is a reflection of the intrinsic qualities of a tumour and as a consequence, will give an indication of features such as to the rapidity of growth and probability of metastasis. In this review, I will concentrate on the relationship of the morphological attributes of breast cancer to underlying molecular events and give examples of how these relate both to long-established taxonomic categories, and to some emerging ones. I will also examine their relationship to predictive markers and to specific biological peculiarities. By molecular techniques, I will, elastically, also encompass some cytogenetic alterations.

\section{DIVERSITY IN BREAST CANCER}

Breast cancer is an extraordinarily diverse group of diseases in terms of presentation, morphology and molecular profile. Since

\footnotetext{
*Correspondence: Professor AM Hanby;

E-mail: Andrew.hanby@ntlworld.com, Andrew.hanby@leedsth.nhs.uk Received 4 October 2004; accepted 7 January 2004; published online 8 February 2005
}

the behaviour and response of these tumours to treatment is also equally disparate, linking these is a worthwhile, but not trivial, task. Established breast cancer taxonomy divides breast cancers into tumours of special type, of which tubular, mucinous, medullary and lobular carcinomas are examples, and ductal carcinoma of no special type (NST) (Ellis et al, 1992). This classification is predicated on the recognition of a feature or suite of features that contribute to a distinctive appearance (special type tumours), or lack of these (tumours of NST). It is worth saying that the classic split between 'lobular' and 'ductal' 'carcinoma' was based on belief that there were distinct microanatomical origins for these tumours; however, the current view is that most breast cancers arise from the terminal duct lobular unit (Wellings et al, 1975). The broad difference between these two groups emanates from their differing molecular profiles. Ductal carcinomas of NST represent the largest group of tumours and contains a diverse group of lesions within which distinct, covert types undoubtedly exist; however, it is the special type tumours that show the most well-documented morphology/molecular profile/behavioural relationships.

\section{LOBULAR CARCINOMA}

Lobular carcinoma shows distinctive clinical features with metastases within coelomic cavities and to odd sites more common than in other tumour types (Harris et al, 1984; Dixon et al, 1991; $\mathrm{du}$ Toit et al, 1991). This tumour also presents a distinctive morphological picture whose key elements include growth of cells in narrow cords - Indian files, a swirling pattern around benign breast tissue, the 'targetoid pattern', often a diffuse growth, skip lesions whereby satellite of tumour are seen separated from the main lesion by uninvolved benign tissue and cellular discohesion. Despite this, 'a precise definition of lobular carcinoma remains elusive' (Di Costanzo et al, 1990). Of the listed features, the discohesion now appears pivotal, since there is inactivation of the E-cadherin gene, either though a truncation mutation (Berx et al, 1995,1996 ) in approximately 50\% (Berx et al, 1996), or methylation of its promoter (Droufakou et al, 2001). E-cadherin is one of the main genes concerned with cell-cell interaction and the elaboration of polarity in epithelial cells. Via interactions with 
614

the catenins and the actin cytoskeleton, E-cadherin is able to influence cell morphology and motility (Bracke et al, 1997; Handschuh et al, 1999). The number of lobular carcinomas showing E-cadherin mutations varies between studies and no doubt reflects pathologist behaviour; diagnosis historically has been made utilising the full suite of features detailed above, but awareness that E-cadherin inactivation as a major molecular alteration with consequent cellular discohesion may have influenced more recent diagnostic behaviour.

\section{MORPHOLOGICAL DIVERSITY IN LOBULAR CARCINOMAS}

Casual observation reveals that even so-called classic pattern lobular carcinomas show morphological variation; however, the molecular correlations for this variety remain uncharted. Some of the more distinct, but rare, variant types do manifest molecular and behavioural differences. In general, these tumours are more aggressive (Dixon et al, 1982). Some exhibit features of apocrine differentiation (Eusebi et al, 1984), which has also been termed the histiocytoid variant because of the resemblance of these cells to histiocytes. Some examples of the pleomorphic variant, which for some may also encompass some tumours with apocrine features (Eusebi et al, 1992), show attributes more in common with highgrade ductal carcinomas, such as a more diverse cytogenetic alterations (see below). There are also therapeutic consequences, and unlike in classical pattern lobular carcinomas, HER2 amplification often occurs.

\section{MUCINOUS CARCINOMA}

These lesions are characterised by tumour cells resting in pools of mucin with manifest as empty spaces disrupting the tissue. It is the type of mucin that these lesions produce that may account, in part, for the distinctive morphology. Benign mammary epithelium and many breast cancers produce transmembrane mucins, mainly from the MUC1 gene (Taylor-papadimitrou et al, 2002). In mucinous carcinomas, there is a switch to the production of gelforming mucins, products of the MUC2 and MUC5 genes (O'Connell et al, 1998). It is easy to see how this could cause the tissue disruption and facilitate the distinct morphology of these lesions. One may speculate that both the volume of mucin contributing to overestimation of tumour size and early detection and the possibility that the ensheathing mucin might hinder the entrance of tumour cells into the vasculature, could contribute to the very good prognosis typical of these tumours. The survival figures of these lesions approaches the age-matched population as long as they are wholly mucinous without any elements of ductal carcinoma NST, that is, they are 'pure' (Fentiman et al, 1997). It is therefore of interest to note that 'impure' elements such as components of ductal carcinoma NST revert or continue to elaborate MUC1 mucins (O'Connell et al, 1998) and tumours exhibiting this do less well.

The mucin profile has other potential therapeutic ramifications; in many breast cancers, the glycosylation of the MUC-1 mucin side chains is altered and the mucin variant presents a potential target for immunotherapy (Taylor-papadimitrou et al, 2002); however, this is not an option for mucinous carcinomas which do not produce MUC-1.

The changes in MUC gene expression are also seen in a spectrum of coexistent changes from mucinous DCIS at the malignant end of the spectrum through to the benign mucocelelike lesions and mucin-filled ducts - implying a field change (O'Connell et al, 1998). Since this mucin may take up calcium, there has been increased detection of benign 'mucinous' lesions (Carder and Liston, 2003) leading to some difficult problems for the Breast Screening Team.
Molecular explanations for some associations with mucinous lesions remain elusive; for example, the association of some mucinous carcinomas with neuroendocrine differentiation (Capella et al, 1980) and the occurrences of mucinous/lobular mixed lesions (Gad and Azzopardi, 1975).

\section{OTHER SPECIAL TYPE CARCINOMAS}

Included within the special type subgroup are a number of lowgrade lesions such as tubular and mucinous carcinomas. Tubular carcinomas typically share the classic $16 \mathrm{q} / 1 \mathrm{q}$ change seen in grade I and lobular tumours (see below) and like lobular carcinomas can be multifocal. As yet, no specific defining abnormalities have been revealed for these tumours. The regular loss of $16 \mathrm{q}$ in these and other breast tumours implies the presence of relevant tumoursuppressor gene(s) on 16q; although various tumour-suppressor genes have been implicated, for example CTCF (Filipopva et al, 1998), none have been proven as pathogenic.

The rest of the special types group includes two generally higher grade types of lesions - metaplastic and medullary carcinoma both of which will be discussed more later, and a number of rarer lesions. Of the latter groups, adenoid-cystic and adenosquamous carcinomas are notable.

\section{MIXED DUCTAL AND LOBULAR CARCINOMAS}

Classic lobular carcinoma and grade I ductal tumours show broad similarities at the cytogenetic level. Cohorts of both tumour types exhibit relatively few changes, when compared with grade III tumours and commonly show loss of at least some of the chromosome arm 16q and gain of $1 \mathrm{p}$; the former including the E-cadherin locus. This suggests that these morphologically dissimilar lesions may be closely related. Mixed ductal and lobular elements in breast cancers are not uncommon and where these morphologies are intermingled, variable methylation of the Ecadherin promoter seems a more plausible explanation for the patchy morphology and E-cadherin expression in these hybrid lesions, than E-cadherin gene mutation (Graff et al, 2000). These findings imply that some lobular and ductal carcinomas are very similar and in some cases represent parts of the same lesion. However, this story is not always so straightforward - some grade I tumours can appear E-cadherin negative by immunohistochemistry and yet form tubular structures - implying a degree of functional redundancy for E-cadherin, with other cadherins accounting for the necessary cell-cell cohesion (Tan et al, 1999). Note that in the UK, it is necessary to meet certain criteria percentages for the different components for the category 'mixed' as a practical expedient dictated by the National Health Service Breast Screening Programme (NHSBSP), but these rules underestimate the number of lesions that have some element of mixed morphology.

\section{GRADE AND TUMOURS OF NST}

Grade has been mentioned several times already. In breast disease it has a specific meaning and is derived using methodology evolved from that documented in a seminal paper by Bloom and Richardson (1957), devised by Scarfe, a pathologist. As originally described, there were inherent imprecisions, and the modified methodology described by Elston and Ellis (1991) is the one that is generally used today. Tumours are given a cumulative score based on the assessment of tubule formation, pleomorphism and mitotic activity, which then allows division into grade I (least 'aggressive'), through to III (most 'aggressive'). The term 'grade' taken at face value could imply a continuum of biological behaviour with progression between grades - so-called 'phenotypic drift'. This 
view has been successfully challenged; several studies indicate that although the boundaries between the grade groups are arbitary, tumours tend not to evolve through grade (Blamey, 1993; Johnson and Shekhdar, 2001). Morphological studies comparing recurrence and metastasis with primary lesions support this view and more recently cytogenetic studies (Roylance et al, 1999). Cytogenetic studies of Pan-grade groups both show evidence of intratumoural heterogeneity (Aubele et al, 1999) and disparate findings between breast cancers with a wide range of changes across the chromosome spreads. In unselected cohorts, no clear pattern emerges since either the cohorts had not been chosen to fully represent all grades or the element of grade had not been included at all. Roylance and co-workers, however, examined the relationship of grade I ductal carcinoma to grade III tumours. The results revealed distinct differences between the two groups; grade I tumours showed a relatively narrow spread of changes notably with loss of $16 \mathrm{q}(65 \%)$ and gain of $1 \mathrm{q}(70 \%)$ being dominant. In grade III lesions, the changes were more diverse. AlThough there were some commoner changes, for example, amplification of $17 \mathrm{q}$ corresponding, none was as frequent as the $16 \mathrm{q} / 1 \mathrm{q}$ gain seen in grade I lesions. Furthermore, while $16 \mathrm{q}$ loss did occur in the grade III group (16\%), this was qualitatively different (Roylance et al, 2002). These results support the view that, in general, grade I tumours are unlikely to evolve to grade III tumours, which is also supported by further evidence discounting the implausibility of regain of genetic material on $16 \mathrm{q}$ in grade III lesions. Curiously, as detailed above, they are more cytogenetically similar to the morphologically dissimilar lobular carcinomas. To crystallize grade I ductal tumours encompass different types to grade III tumours and these observations give reasonable justification for 'within grade' research.

\section{GRADING IDIOSYNCRASY}

Confusingly, for the non-initiated grading runs in parallel with the taxonomic system that divides breast carcinomas into ductal carcinomas of NST, lobular carcinomas and several varieties of special type carcinomas. Additionally, the several classifications used for Ductal carcinoma in situ also use the term 'grade', but generally refer only to the nuclear characterisic of the noninvading malignant cells of this precursor lesion (Douglas-Jones et al, 1996), whereas modified Bloom and Richardson grading is derived from a composite of nuclear pleomorphism, tubule formation and mitotic activity. This explains why it is possible to have a grade I tumour arising from high-grade DCIS.

\section{HIGH-GRADE TUMOURS: MORE DIVERSITY}

Even within the high-grade group of tumours, behavioural diversity in terms of disease progression, survival and response to therapy is high. This is matched by morphological and molecular heterogeneity within this group. There are however some distinct molecular markers which both internally divide this tumour group and also, in some cases, help explain distinctive biology and morphology.

\section{HER2 AMPLIFIED TUMOURS}

As well as predicting for response to Herceptin, HER2 amplification is interesting with regards to morphological correlations. These tumours are associated with a poor prognosis which is, however, not independent of grade. HER2-amplified tumours are typically high grade and show increased mitotic activity, a high degree of nuclear pleomorphism and an association with comedo necrosis (Berger et al, 1988; Borg et al, 1989, 1991) in associated DCIS. One of the most notable is the observation that up to $91 \%$ of
Paget's disease of the nipple shows this phenomenon (Lammie et al, 1989). In vitro studies may explain this; amplication of HER2 in breast cell lines causes them to become epidermotropic (Schelfhout et al, 2000). Another notable observation is that while $60 \%$ of pure DCIS in one study exhibited evidence of HER2 gene amplification, this dropped to $25 \%$ of with infiltrating ductal carcinoma, co-existent with the difference between in situ and invasive being even more marked when high nuclear grade lesions were matched (Barnes et al, 1992). Furthermore, HER2-amplified DCIS is often very extensive. Taken together, the latter two observations imply that HER2-amplified breast cancer may have a prolonged in situ phase allowing widespread duct colonisation before invasion. They also suggest that there is a population of other, different, high-grade breast cancers with a short in situ phase prior to invasion.

\section{BRCA-RELATED TUMOURS}

BRCA1-related tumours can have distinct morphological features, similar, if not identical, to 'medullary' carcinoma (Eisinger et al, 1998). Medullary carcinoma is interesting on many levels and has both the attributes of a special type cancer and a high-grade lesion. Reproducibility of diagnosis is problematic (Gaffey et al, 1995) and many, including myself avoid using the term, since the good prognosis related to this lesion in the original work has been difficult to reproduce in subsequent series. A notable feature of BRCA-1-related tumours is the possession of high mitotic rates (Armes et al, 1999), particularly if the mutation is at the $5^{\prime}$ end (Breast-Cancer-Linkage-Consortium, 1997). Correlating LOH of the BRCA-1 locus to morphology in a study of sporadic tumours also showed an association with extremely high mitotic counts occasionally exceeding 100 per 10 high power fields. HER2 amplification is extremely rare in tumours associated with germline mutations of BRCA-1, which correlates well with the absent or sparse amounts of DCIS typically seen.

For tumours associated with germline mutation of BRCA-2, an association with lobular carcinomas (Armes et al, 1999) has been suggested but since then no firm morphological correlation has been proven.

\section{METAPLASTIC CARCINOMAS}

This group of tumours show a wide variety of patterns but are linked by the propensity of the neoplastic population to take on the characteristics of a cell presumed to be other than the originating type. As a consequence, squamous cell carcinomas of the breast are encompassed in this group. However, the majority show the phenomenon of epithelial-mesenchymal transformation (EMT), whereby the epithelium switches to a mesenchymal phenotype (Gilles and Thompson, 1996). This may produce a nonspecific sarcomatous appearace, or even produce a tumour exhibiting features indicative of specific mesenchymal differentiation - such as osteosarcomatous differentiation. A number of generic changes such as downregulation of E-cadherin, keratin profile alterations and upregulation of vimentin occur in the EMT seen in these lesions (Gilles and Thompson, 1996; Fuchs et al, 2002) and, as such, mirror the changes of EMT which necessarily occur during embryonic development.

Metaplastic carcinomas have been divided into five groups and for one of these, matrix-producing carcinoma, MIC-2 upregulation has been claimed as distinctive (Milanezi et al, 2001) in a small series of lesions; it remains to be seen as to whether this will hold true when larger cohorts are studied. What is emerging, however, is the view that many of these lesions show evidence of basal/ myoepithelial differentiation (Oberman, 1987; Wargotz et al, 1989; Foshini and Eusebi, 1998). 


\section{BASAL/MYOEPITHELIAL DIFFERENTIATION IN BREAST CANCERS}

As above, at least some metaplastic carcinomas have features indicative of basal/myoepithelial differentiation, unlike most breast cancers that exhibit features of the inner, luminal cells of the breast. Initial studies of tumours with distinctive morphological features, notably large, acellular central zones, which 'resemble burnt ruins after a forest fire' (Tsuda et al, 1999), showed that these too often had basal/myoepithelial features. These tumours showed a relatively poor outcome in comparison to other breast carcinomas (Tsuda et al, 2000). These findings were also associated with distinct morphology with spindle cells, central fibrosis and necrosis and very high mitotic rate more common (Tsuda et al, 2000). Finally, attention to the metastatic patterns of the tumours in this cohort support the view that these cancers are a distinct tumour type; metastasis is less common, but when it does occur, it happens more quickly and more often goes to the brain and lungs than other breast cancers (Tsuda et al, 2000).

\section{DO MORPHOLOGICAL OBSERVATIONS MATTER AND WHAT DOES THE FUTURE HOLD?}

There is no doubt that interobserver variability make morphology an imprecise tool (Cserni, 1999; Dunne and Going, 2001), but there is no evidence so far that any combination of molecular attributes can be used to predict the morphological, behavioural and drug response profiles of all breast cancers. Certainly array-based studies have shown distinct expression patterns related to drug response and to survival data, but as yet do not supplant morphology in routine use. Many of the distinct morphologies described have known distinct molecular attributes; if it looks different, it probably is different. Recognition of distinct lesions is important to factor into the study of breast cancer biology, in particular the design of study cohorts and trial analysis since they may present distinct molecular targets and/or response profiles. It may be that forms of molecular profiling techniques will ultimately replace morphological analysis in tumour classification (Bell, 1999; Alizadeh et al, 2001), but for now this morphology continues to make an important contribution to the investigation of the diverse group of diseases we call breast cancer.

\section{REFERENCES}

Alizadeh AA, Ross DT, Perou CM, Van De Rijn M (2001) Towards a novel classification of human malignancies based on gene expression patterns. J Pathol 195: $41-52$

Armes JE, Trute L, White D, Southey MC, Hammet F, Tesoriero A, Hutchins A-M, Dite GS, McCredie MRE, Giles GG, Hopper JL, Venter DJ (1999) Distinct molecular pathogenesis of early-onset breast cancers in BRCA1 and BRCA2 mutation carriers: a population-based study. Cancer Res 59: 2011-2017

Aubele M, Mattis A, Zitzelsberger H, Walch A, Kremer M, Hutzler P, Hofler $\mathrm{H}$, Werner M (1999) Intratumoral heterogeneity in breast carcinoma revealed by laser-microdissection and comparative genomic hybridization. Cancer Genet Cytogenet 110: 94-102

Balslev I, Axelsson CK, Zedeler K (1994) The Nottingham Prognostic index applied to 9,149 patients from the Danish Breast Cancer Cooperative Group (DBCCG). Breast Cancer Res Treat 32: 281-290

Barnes DM, Bartkova J, Camplejohn RS, Gullick WJ, Smith PJ, Millis RR (1992) Overexpression of the c-erbB-2 oncoprotein: why does this occur more frequently in ductal carcinoma in situ than in invasive mammary carcinoma and is this of prognostic significance? Eur J Cancer 28: $644-648$

Bell JI (1999) Clinical research is dead; long live clinical research. Nat Med 5: $477-478$

Berger MS, Locher W, Saurer S, Gullick WJ, Waterfield MD, Groner B, Hynes NE (1988) Correlation of c-erbB-2 gene amplification and protein expression in human breast carcinoma with nodal status and nuclear grading. Cancer Res 48: $1238-1243$

Berx G, Cleton-Jansen AM, Nollet F, Leeuw WJFd, Vijver MJvd, Cornelisse C, Roy Fv (1995) E-cadherin is a tumour/invasion suppressor gene mutated in human lobular breast cancers. EMBO J 14: 6107-6115

Berx G, Cleton-Jansen AM, Strumane K, Leeuw WJFd, Nollet F, Roy Fv, Cornelisse C (1996) E-cadherin is inactivated in a majority of invasive human lobular breast cancers by truncation mutations throughout its extracellular domain. Oncogene 13: 1919-1925

Blamey RW (1993) Phenotypic drift does not happen but lots of interesting things do. The Breast 2: 190

Bloom HJG, Richardson WW (1957) Histological grading and prognosis in breast cancer. A study of 1,409 cases of which 359 have been followed for 15 years. Br J Cancer 11: $359-377$

Borg A, Baldetorp B, Ferno M, Killander D, Olsson H, Sigurdsson H (1991) erbB-2 amplification in breast cancer with a high rate of proliferation. Oncogene 60: 137-143

Borg A, Linell F, Idvall I, Johansson S, Sigurdsson H, Ferno M, Killander D (1989) HERS/neu amplification and comedo type breast carcinoma. Lancet I: $1268-1269$

Bracke ME, Depypere H, Labit C, Marck VV, Vennekens K, Vermeulen SJ, Maelfait I, Philippe J, Serreyn R, Mareel MM (1997) Functional downregulation of the E-cadherin/catenin complex leads to loss of contact inhibition of motility and of mitochondrial activity, but not of growth in confluent epithelial cultures. Eur J Cell Biol 74: 342-349

Breast-Cancer-Linkage-Consortium (1997) Pathology of familial breast cancer: differences between breast cancers in carriers of BRCA1 or BRCA2 mutations and sporadic cases. Lancet 349: 1505-1510

Capella C, Eusebi V, Mann B, Azzopardi JG (1980) Endocrine differentiation in mucoid carcinoma of the breast. Histopathology 4: 613-630

Carder PJ, Liston JC (2003) Will the spectrum of lesions prompting a 'B3' breast core biopsy increase the benign biopsy rate. J Clin Pathol 56: $133-138$

Cserni G (1999) Reproducibility of a diagnosis of invasive lobular carcinoma. J Surg Oncol 70: 217-221

Di Costanzo D, Rosen PP, Gareen I, Franklin S, Lesser M (1990) Prognosis in infiltrating lobular carcinoma. An analysis of 'classical' and variant tumours. Am J Surg Pathol 14: 12-23

Dixon AR, Ellis IO, Elston CW, Blamey RW (1991) A comparison of the clinical metastatic patterns of invasive lobular and ductal carcinomas of the breast. Br J Cancer 63: 634-635

Dixon JM, Anderson TJ, Page DL, Lee D, Duffy SW (1982) Infiltrating lobular carcinoma of the breast. Histopathology 6: 149-161

Douglas-Jones AG, Gupta SK, Attanoos RL, Morgan JM, Mansel RE (1996) A critical appraisal of six modern classifications of ductal carcinoma in situ of the breast (DCIS): correlation with grade of associated invasive carcinoma. Histopathology 29: 397-409

Droufakou S, Deshmane V, Hanby A, Tomlinson I, Hart I (2001) Multiple ways of silencing E-cadherin gene expression in lobular carcinoma of the breast. Int J Cancer 92: 404-408

Dunne B, Going JJ (2001) Scoring nuclear pleomorphism in breast cancer. Histopathology 39: 259-265

du Toit R, Locker AP, Ellis IO, Elston CW, Nicholson RI, Robertson JFR, Blamey RW (1991) An evaluation of differences in prognosis, recurrence patterns and receptor status between invasive lobular and other invasive carcinomas of the breast. Eur J Surg Oncol 17: 251-257

Eisinger F, Jacquemier J, Charpin C, Stoppa-Lyonnet D, Paillerets BB-d, Peyrat J, Longy M, Guinebretiere J, Sauvan R, Noguchi T, Birnbaum D, Sobol H (1998) Mutations at BRCA1: the medullary carcinoma revisited. Cancer Res 58: 1588-1592

Ellis IO, Galea M, Broughton N, Locker A, Blamey RW, Elston CW (1992) Pathological prognostic factors in breast cancer. II. Histological type. Relationship with survival in a large study with long term follow-up. Histopathology 20: 479-489

Elston CW, Ellis IO (1991) Pathological prognostic factors in breast cancer. I. The value of histological grade in breast cancer: experience from a large study with long-term follow-up. Histopathology 19: 403-410

Eusebi V, Betts C, Haagensen D, Gugliotta P, Bussolati G, Azzopardi JG (1984) Apocrine differentiation in lobular carcinoma of the breast. Hum Pathol 15: 134-140 
Eusebi V, Magalhaes F, Azzopardi JG (1992) Pleomorphic lobular carcinoma of the breast: an aggressive tumor showing apocrine differentiation. Hum Pathol 23: 655-662

Fentiman IS, Millis RR, Smith P, Ellul JPM, Lampejo O (1997) Mucoid breast carcinomas: histology and prognosis. $\mathrm{Br} J$ Cancer 75: $1061-1065$

Filipopva GN, Lindblom A, Meinke LJ, Klenova EM, Neiman PE, Collins SJ, Doggett NA, Lobanenkov VV (1998) A widely expressed transcription factor with multiple DNA sequence specificity, CTCF, is localised at chromosome segment 16q22.1 within one of the smallest regions of overlap for common deletions in breast and prostate cancers. Genes, Chromosomes Cancer 22: $26-36$

Foshini MP, Eusebi V (1998) Carcinomas of the breast showing myoepithelial cell differentiation. Virchows Arch 432: 303-310

Fuchs I, Lichtenegger W, Buehler H, Henrich W, Stein H, Kleine-Tebbe A, Schaller G (2002) The prognostic significance of epithelial-mesenchymal transition in breast cancer. Anticancer Res 22: 3415-3419

Gad A, Azzopardi JG (1975) Lobular carcinoma of the breast: a special variant of mucin-secreting carcinoma. J Clin Pathol 28: 711-716

Gaffey MJ, Mills SE, Frierson HF, Zarbo RJ, Boyd JC, Simpson JF, Weiss LM (1995) Medullary carcinoma of the breast: interobserver variability in histopathologic diagnosis. Mod Pathol 8: $31-38$

Gilles C, Thompson EW (1996) The epithelial to mesenchymal transition and metastatic progression in carcinoma. Breast J 2: 83-96

Graff JR, Gabrielson E, Fujii H, Baylin SB, Herman JG (2000) Methylation patterns of the E-cadherin $5^{\prime} \mathrm{CpG}$ island are unstable and reflect the dynamic, heterogeneous loss of E-cadherin expression during metastatic progression. J Biol Chem 275: $2727-2732$

Handschuh G, Candidus S, Luber B, Reich U, Schott C, Oswald S, Becke H, Hutzler P, Birchemier W, Hofler H, Becker K-F (1999) Tumour associated E-cadherin mutations alter cellular morphology decrease adhesion and increase cellular motility. Oncogene 18: $4301-4312$

Harris M, Howell A, Chrissohou M, Swindell RIC, Hudson M, Sellwood RA (1984) A comparison of the metastatic pattern of infiltrating lobular and infiltrating ductal carcinoma of the breast. $\mathrm{Br} J$ Cancer 50: $23-30$

Johnson A, Shekhdar J (2001) Does breast cancer grade worsen with time? Evidence from breast screening. Breast Cancer Res Treat 68: $261-271$
Lammie GA, Barnes DM, Millis RR, Gullick WH (1989) An immunohistochemical study of the presence of c-erbB-2 protein in Paget's disease of the nipple. Histopathology 15: 505-514

Milanezi F, Pereira EM, Ferreira FV, Leitao D, Schnitt FC (2001) CD99/ MIC-2 surface protein in breast carcinomas. Histopathology 39: $578-583$ Oberman HA (1987) Metaplastic carcinoma of the breast. Am J Surg Pathol 11: $918-929$

O'Connell JT, Shao Z, Drori E, Basbaum CB, Barsky SH (1998) Altered mucin expression is a field change that accompanies mucinous (colloid) breast carcinoma. Hum Pathol 29: 1517-1523

Roylance R, Gorman P, Hanby A, Tomlinson I (2002) Allelic imbalance analysis of chromosome $16 \mathrm{q}$ shows that grade I and grade III invasive ductal carcinomas follow different genetic pathways. J Pathol 196: $32-36$ Roylance R, Gorman P, Harris W, Liebmann R, Barnes D, Hanby A, Sheer D (1999) Comparative hybridisation of breast tumours stratified by histological grade reveals new insights into the biological progression of breast cancer. Cancer Res 59: 1433 - 1436

Schelfhout VRJ, Coene ED, Delaey B, Thys S, Page DL, Potter CRD (2000) Pathogenesis of Paget's disease: epidermal heregulin - a motility factor, and the HER receptor family. J Natl Cancer Inst 92: 622-628

Tan DSP, Potts HWW, Leong ACK, Gillett CE, Skilton D, Harris WH, Liebmann RD, Hanby AM (1999) The biological and prognostic significance of cell polarity and E-cadherin in grade I infiltrating ductal carcinoma of the breast. J Pathol 189: 20-27

Taylor-papadimitrou J, Burchell JM, Plunkett T, Graham R, Correa I, Miles D, Smith M (2002) MUC1 and the immunobiology of cancer. J Mammary Gland Biol Neoplasia 7: 209-221

Tsuda H, Takarabe T, Hasegawa F, Fukutomi T, Hirohashi S (2000) Large, central acellular zones indicating myoepithelial tumor differentiation in high-grade invasive ductal carcinomas as markers of predisposition to lung and brain metastases. Am J Surg Pathol 24: 197-202

Tsuda H, Takarabe T, Hasegawa T, Murata T, Hirohashi S (1999) Myoepithelial differentiation in high-grade invasive ductal carcinomas with large central acellular zones. Hum Pathol 30: 1134-1139

Wargotz ES, Deos PH, Norris HJ (1989) Metaplastic carcinomas of the breast. II. Spindle cell carcinoma. Hum Pathol 20: $732-740$

Wellings SR, Jensen HM, Marcum RG (1975) Atlas of subgross pathology of the human breast with special reference to possible cancerous lesions. J Natl Cancer Inst 55: $231-273$ 